\title{
T2 Stage Finding
}

National Cancer Institute

\section{Source}

National Cancer Institute. T2 Stage Finding. NCI Thesaurus. Code C48724.

A general term that refers to a TNM finding of primary tumor growth beyond the level of in situ cancer, minimal subepithelial invasion, or minimal greatest diameter. The definition of T2 TNM finding depends on the specific type of cancer that it refers to; for example, for breast cancer it refers to primary tumor that is more than $2.0 \mathrm{~cm}$, but not more than $5.0 \mathrm{~cm}$ in greatest dimension; for cutaneous melanoma it refers to primary tumor that is 1.01 to $2 \mathrm{~mm}$ in thickness, with or without ulceration; for colorectal cancer it refers to primary tumor with invasion into the muscularis propria; and for bladder cancer it refers to primary tumor with invasion into the muscle layer. 